\title{
O EXERCÍCIO DA PARENTALIDADE QUANDO O FILHO É PORTADOR DE NECESSIDADES ESPECIAIS
}

\author{
Elimar Szaniawski ${ }^{1}$ \\ Luciana Berlini ${ }^{2}$
}

\section{Resumo}

O exercício da autoridade parental requer uma nova interpretação do Direito Civil, especificamente quando a prole é portadora de necessidades especiais. Isso porque, a combinação da peculiar condição de portador de necessidades especiais, conjugada com o fato de ser criança ou adolesceste e, portanto, incapaz, acentua a situação de vulnerabilidade enfrentada. Assim, a proteção da população infanto-juvenil inicia-se pela análise do exercício da autoridade parental, já que os pais são, em regra, os representantes legais de seus filhos menores, de tal modo que é a partir dessas relações que será possível observar o respeito dos direitos e garantias das crianças e adolescentes, especialmente quando portadoras de necessidades especiais, traçando as novas diretrizes estabelecidas pela Lei Brasileira de Inclusão da Pessoa com Deficiência (Estatuto da Pessoa com Deficiência).

Palavras-chave: Exercício da Autoridade Parental. Filho Portador de Necessidades Especiais.

\section{INTRODUÇÃO}

O exercício da parentalidade, como pressuposto inerente ao poder familiar, requer uma nova interpretação do Direito Civil, especificamente quando a prole é portadora de necessidades especiais.

Isso porque, os direitos dos portadores de necessidades especiais configuram uma nova demanda social, tanto é assim que no dia 06 de julho de 2015 foi publicada a a Lei Brasileira de Inclusão da Pessoa com Deficiência (Estatuto da Pessoa com Deficiência), "destinada a assegurar e a promover, em condições de igualdade, o exercício dos direitos e das liberdades fundamentais da pessoa com deficiência, visando à sua inclusão social e cidadania." (BRASIL, 2015).

Acrescente-se a isso, a combinação da peculiar condição de portador de necessidades especiais, conjugada com o fato de ser menor e, portanto, incapaz, o que acentua a situação de vulnerabilidade enfrentada.

\footnotetext{
${ }^{1}$ Doutor em Direito, pela Universidade Federal do Paraná. Professor Associado IV na graduação e professor pesquisador no Programa de Pós-graduação em Direito, da UFPR. Conselheiro editorial - Revista Jurídica Mater Dei. Advogado. E-mail: zani@microcomp.com.br

${ }^{2}$ Pós Doutoranda em Direito pela Universidade Federal do Paraná. Professora Adjunta da Universidade Federal de Lavras. Professora do curso de Pós-Graduação em Dano Corporal pela Universidade de Coimbra/POR. E-mail: luberlini@yahoo.com.br vol.09, nº. 01, Rio de Janeiro, 2016.pp. 425-440 
Assim, a peculidar condição de desenvolvimento e a de civilmente incapazes demanda uma nova interpretação para as relações parentais dessa natureza, quando o exercício da parentalidade se dá nas hipóteses em que o filho é deficiente, ou seja, "aquele que tem impedimento de longo prazo de natureza física, mental, intelectual ou sensorial, o qual, em interação com uma ou mais barreiras, pode obstruir sua participação plena e efetiva na sociedade em igualdade de condições com as demais pessoas", como define o artigo 2. da Lei 13.146/2015. (BRASIL, 2015).

Os cuidados especiais, a matrícula em escola (especializada ou não), o tratamento diferenciado, o trabalho, a inclusão social e familiar são apenas alguns dos aspectos que geram a necessidade de se repensar a atuação dos genitores no exercício da autoridade parental.

A proteção da população infanto-juvenil inicia-se pela análise do exercício da autoridade parental, já que os pais são, em regra, os representantes legais de seus filhos menores, de tal modo que é a partir dessas relações que será possível observar o respeito dos direitos e garantias das crianças e adolescentes, especialmente quando portadoras de necessidades especiais.

\section{DA AUTORIDADE PARENTAL: PORQUE A INCLUSÃO COMEÇA EM CASA}

O exercício da autoridade parental é primordial na proteção e promoção dos direitos das crianças e dos adolescentes, especialmente quando a prole precisa de cuidados especiais.

Hoje, com o atual Código Civil, o poder familiar trata da autoridade que ambos os pais, em igualdade de condições, exercem em relação aos seus filhos menores, não emancipados, durante a relação conjugal ou mesmo fora dela. Por isso:

O entendimento que prepondera é de que o poder familiar seria um conjunto de direitos e deveres referentes à pessoa e ao patrimônio do menor não emancipado, a que os pais estão atrelados, sendo composto por um rol de deveres para com os filhos, principalmente os de cunho material, intelectual, além da gerência dos bens que possam ter. Assim, sobreporia o compêndio de deveres aos poderes. (TEIXEIRA, 2008, p. 95).

Embora a atual legislação civil tenha adotado a expressão poder familiar em substituição a de pátrio poder, muitos doutrinadores (LÔBO, 2006; FACHIN, 1999; TEIXEIRA, 2008) têm criticado a terminologia. Alegam que autoridade parental definiria melhor o instituto em sua concepção mais atual, por referir-se a um poder legítimo e não simplesmente à possibilidade de coação e imposição de deveres.

O referido instituto, por aproximar-se mais da noção de múnus, numa visão dialética de seu exercício, não deveria ser denominado poder, conforme critica a doutrina mais atenta, alertando que os filhos não podem ser objeto dessa relação, já que foram elevados à condição de sujeitos de direitos e deveres pela Constituição da República de 1988 e pelo Estatuto da Criança e do Adolescente, com o sistema de proteção integral, motivo pelo qual optam por denominá-lo de autoridade parental. (BERLINI, 2014, p.52) 
Dessa forma, como adverte Luiz Édson Fachin:

Não se trata de "poder", nem propriamente de função. Não há relação de subordinação. É mais que um "direito-dever", expressão híbrida equivocada. [...] As características da autoridade parental:

1. É um múnus, significado que transcende o interesse pessoal, e o exercício da autoridade parental não consiste necessariamente no atendimento do interesse privado. $\mathrm{O}$ direito respectivo também está submetido a certos limites, por exemplo, o respeito à liberdade religiosa ou crenças;

2. É irrenunciável, mas pode ser destituído do exercício do direito;

3. É inalienável, não suscetível de ser transferido;

4. É imprescritível. (FACHIN, 1999, p. 222;225).

Essa noção de "direito-dever" trazida pelo referido autor condiz com a noção do artigo 227 da Constituição da República de 1988, ao trazer o sistema de proteção integral de crianças e adolescentes, deixando claro que além de direitos o instituto da autoridade parental rege-se por uma série de deveres.

Ocorre que a mudança na concepção do instituto deu-se por um processo longo que acompanhou toda uma transformação histórica e cultural, que teve na Constituição da República de 1988 sua base.

Esse longo percurso ainda não chegou ao seu fim. Quando se trata do exercício da parentalidade sendo o filho portador de necessidades especiais muitas dúvidas ainda são levantadas e a atuação dos pais muitas vezes precisa ser repensada, para que consigam qualitativamente atender ao melhor interesse do filho na dinâmica dessa relação parental.

A relação paterno-filial na concepção atual ultrapassa o caráter de dependência dos filhos para atingir o fundamento principal de formação das relações familiares, qual seja, o afeto estabelecido entre os sujeitos dessa relação.

Considera-se assim, que a "afetividade é necessariamente presumida nas relações entre pais e filhos, ainda que na realidade da vida seja malferida, porque esse tipo de parentesco jamais se extingue”. (LÔBO, 2002, p. 98).

E dessa noção pode-se inferir que, ainda que dependentes e frágeis, os filhos menores são sujeitos de direitos, excluindo qualquer possibilidade de subserviência desses filhos para com os pais que se pretendam dominadores.

Há em diversas sociedades e também na sociedade brasileira uma "cultura", comum a todas as classes sociais, que reflete a dificuldade de reconhecer o outro como um sujeito de direito, e que permite práticas de violência corporal das mais variadas; trata-se de uma verdadeira "mania de bater". (LONGO, 2002, p. 20).

Contemporaneamente, a razão de ser da autoridade parental decorre da relação paterno-filial em si, na qual os filhos não podem ser concebidos como coisa, como objetos de uma relação jurídica, há uma precedência na determinação externa da vida dos filhos ${ }^{3}$, precedência essa que deve ser dada aos filhos, apenas sucessivamente aos pais e ao Estado, pois os filhos, ainda que menores e portadores de necessidades especiais, são sujeitos de direitos, como foi já foi dito, atentando que tal precedência variará de acordo com a idade e a maturidade da prole,

${ }^{3}$ Expressão utilizada pela professora Giselda Hironaka (2002, p.417). 
sempre em consonância com o melhor interesse da criança e do adolescente.

A autoridade paterna existe somente enquanto corresponde a uma obrigação, obrigação fundamentalmente de prover o sustento e a formação; mas essa obrigação é definida cada vez mais pelas necessidades dos filhos e cada vez menos pelos arbítrios dos pais ou do pai. (HIRONAKA, 2002, p. 426-427).

Com isso, a autoridade parental apresenta-se como o exercício de um "direito-dever" dos pais, sempre em benefício dos filhos, daí sua limitação e, por conseguinte, a vedação a qualquer tipo de dano que os pais possam causar ou não evitar em relação aos seus filhos.

Dessa forma, dentre as situações jurídicas subjetivas, a autoridade parental refere-se ao exercício de direitos e deveres atribuídos pelo Estado aos pais, em favor dos filhos menores. (PERLINGIERI, 2002, p. 107).

$\mathrm{Na}$ concepção atual do instituto, todo filho deve ser percebido como destinatário da autoridade parental, sem distinção entre eles, conforme trouxe a Constituição da República de 1988. Essa regra independe do estado civil dos pais, uma vez que a autoridade parental decorre da filiação e não do casamento.

Portanto, a autoridade parental, quanto à sua titularidade e o seu exercício, não pode ser alterada no ordenamento jurídico brasileiro, nos casos de separação, divórcio ou mesmo anulação de casamento, permanecendo, nesses casos, para ambos os genitores, com todas as suas características.

Em outras palavras:

O exercício do poder familiar não é inerente à convivência dos cônjuges ou companheiros. No caso de nova família, a lei põe a salvo qualquer espécie de interferência do novo parceiro à relação entre pais e filhos, exatamente porque o princípio norteador dessa proibição é conformado ao princípio da prioridade absoluta da criança e do adolescente. (ALBUQUERQUE, 2004, p. 169).

O exercício da autoridade parental, por sua vez, como prevê o Código Civil ocorre em nove hipóteses não taxativas, quais sejam:

Art. 1.634. Compete a ambos os pais, qualquer que seja a sua situação conjugal, o pleno exercício do poder familiar, que consiste em, quanto aos filhos:

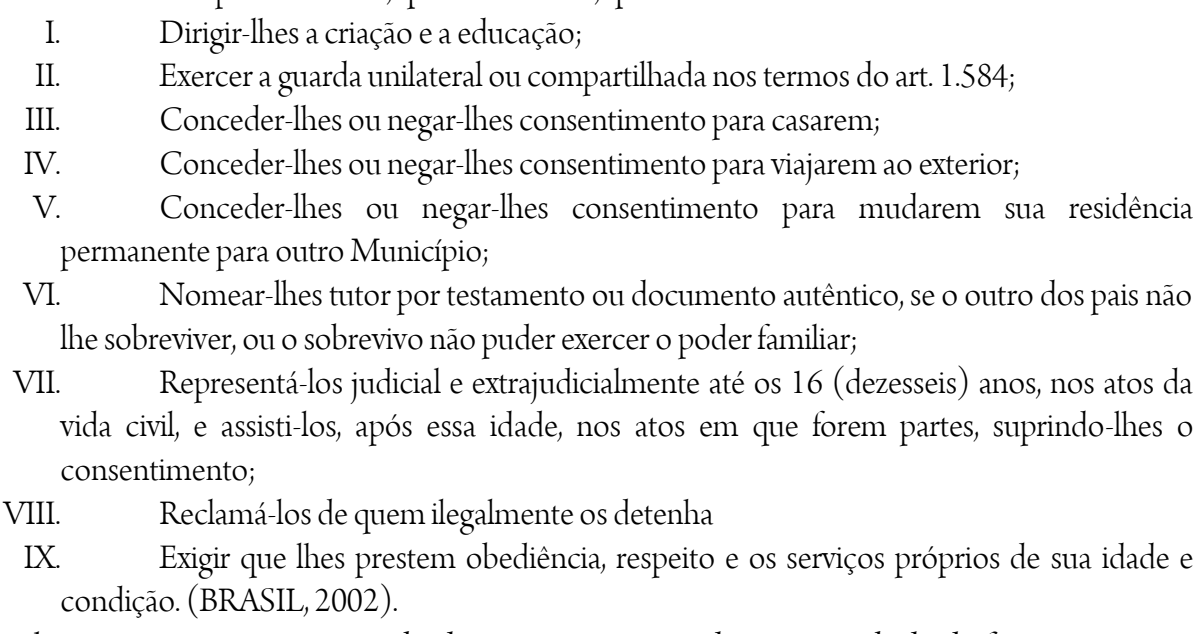

Com relação ao último inciso, no tocante à obediência, esta não pode ser concebida de forma irrestrita, uma vez que a criança e o adolescente são sujeitos de direito. Devem sim obediência aos pais, mas dentro da 
conjugação liberdade e responsabilidade.

Cumpre destacar, ainda, que o exercício da autoridade parental evoca a responsabilidade do pai e da mãe na criação e proteção dos filhos de forma a assegurar os direitos básicos previstos no artigo 227 da Constituição da República de 1988.

No Estatuto da Criança e do Adolescente o exercício da autoridade parental está previsto no artigo 22, em plena compatibilidade com o Código Civil de 2002.

Assim, as normas atinentes à autoridade parental, tanto na perspectiva do Código Civil, da Constituição da República e do Estatuto da Criança e do Adolescente, abrangem as relações patrimoniais e existenciais próprias da filiação, sendo que os menores portadores de necessidades especiais contam com o mesmo sistema de proteção integral, mas que deve ser interpretado de maneira peculiar no exercício da parentalidade, aplicado de forma especial na exata medida em que se desigualam.

Nesse sentido:

O fato de as crianças com deficiências serem incapazes de se defenderem a si próprias, ficarem muitas vezes sozinhas em casa e serem subvalorizadas por aqueles que as rodeiam, também as torna particularmente vulneráveis ao abuso físico, sexual e emocional. Estas crianças também têm menos probabilidade do que os seus irmãos de frequentarem a escola, de irem em excursões, de passarem por situações onde tenham de resolver problemas ou de participarem nos trabalhos domésticos da família. Como resultado, tornam-se adultos desprovidos de poder, incapazes de tomarem decisões, de resolverem problemas ou de assumirem a iniciativa. (JONES, 2002, p. 34).

Assim, quando os genitores não atuam de forma cuidadosa, considerando as limitações e promovendo o bem estar de seus filhos, pode ocorrer o agravamento da própria deficiência.

Ao longo da história a atuação dos pais em relação aos seus filhos sempre foi determinante. Em Esparta os filhos recém-nascidos com alguma espécie de deformação eram condenados à morte, pois além de serem tratados como aberração, simbolizavam, ainda, maus presságios para a família.

O povo espartano, por exemplo, arremessava idosos e recém-nascidos deformados do alto do Monte Taijeto. [...] Os brâmanes eliminavam recém-nascidos defeituosos e velhos enfermos, por considerá-los imprestáveis aos interesses comunitários. Na Índia, lançavam no Ganges os incuráveis [...] Na antiguidade romana, Cícero afirmava (De Legibus, III, 8, 19) que era dever do pai matar filho disforme [...] Os celtas matavam crianças disformes, velhos inválidos e doentes incuráveis. (DINIZ, 2007c, p. 341).

O mesmo acontecia (e muito provavelmente acontece) em algumas tribos indígenas. É exatamente por isso, que se desconhece a existência de crianças indígenas com algum tipo de deficiência. Para as comunidades indígenas o novo membro nasce para contribuir para a vida desta comunidade, o que para eles é incompatível com a deficiência, motivo pelo qual, acabam por sacrificar esses neonatos deficientes, por acreditarem que ele é desnecessário, inútil.

Entre os índios brasileiros, o infanticídio foi sendo abolido à medida que se aculturavam. Mas ele resiste, principalmente, em tribos remotas - e com o apoio de antropólogos e a vol.09, nº. 01, Rio de Janeiro, 2016.pp. 425-440 
tolerância da Funai. É praticado por, no mínimo, treze etnias nacionais. Um dos poucos levantamentos realizados sobre o assunto é da Fundação Nacional da Saúde. Ele contabilizou as crianças mortas entre 2004 e 2006 apenas pelos ianomâmis: foram 201. Mesmo índios mais próximos dos brancos ainda praticam o infanticídio. Os camaiurás, que vivem em Mato Grosso, adoram exibir o lado mais vistoso de sua cultura. Em 2005, a tribo recebeu dinheiro da $\mathrm{BBC}$ para permitir que lutadores de judô e jiu-jitsu disputassem com seus jovens guerreiros a luta huka-huka, parte integrante do ritual do Quarup, em frente às câmeras da TV inglesa. Um ano antes, porém, sem alarde, os camaiurás enterraram vivo o menino Amalé, nascido de uma mãe solteira. Ele foi desenterrado às escondidas por outra índia que, depois de muita insistência, teve permissão dos chefes da tribo para adotá-lo. (COUTINHO, 2007, p. 106).

Questão tormentosa enfrentar a cultura indígena ou tentar estabelecer direitos humanos universais, mesmo porque, foge ao escopo do presente trabalho. Mas, a observância dos maus-tratos praticados por genitores contra crianças e adolescentes enfrenta sim este problema histórico e cultural, mesmo nos dias atuais e nas civilizações mais desenvolvidas.

Percebe-se, na verdade, que a questão dos portadores de necessidades especiais é vista pelo Estado, muito mais pelo lado econômico do que pelo social. Custa caro para o Estado manter um portador de necessidades especiais ocioso e estima-se que haja 120 milhões de crianças portadoras de deficiências. ${ }^{4}$

Embora representem um número expressivo, no Brasil e no mundo, os portadores de necessidades especiais sofrem diversos tipos de exclusão.

No Brasil, segundo estabelece a Política Nacional de Saúde da Pessoa Portadora de Deficiência, entre as deficiências admitidas estão a deficiência mental, motora, auditiva, visual e múltipla, por serem as mais abrangentes e freqüentes, constantes da Classificação da OMS. (BRASIL, 2010).

A definição objetivamente prevista no ordenamento jurídico brasileiro, que determina quem são os portadores de necessidades especiais está nas leis n. ${ }^{\circ}$ 10.048, de 8 de novembro de 2000 (BRASIL, 2000a), e n. ${ }^{\circ}$ 10.098, de 19 de dezembro de 2000 (BRASIL, 2000b).

Não é demais esclarecer que a incapacidade física nada tem a ver com a incapacidade jurídica, que em um rol taxativo presente no Código Civil ${ }^{5}$, determina quem são os absolutamente incapazes e os relativamente incapazes de praticarem sozinhos os atos da vida civil.

Por isso, ser portador de necessidades especiais não é ser incapaz ${ }^{6}$ e ser incapaz não é sinônimo de ser

\footnotetext{
${ }^{4}$ Estimativa dos números das crianças com incapacidades ligeiras, moderadas ou severas. (SAVE..., 2011).

${ }^{5}$ Artigos $3^{\circ}$ e $4^{\circ}$.

${ }^{6}$ Art. $6^{\circ}$ A deficiência não afeta a plena capacidade civil da pessoa, inclusive para:

I. Casar-se e constituir união estável;

II. Exercer direitos sexuais e reprodutivos;

III. Exercer o direito de decidir sobre o número de filhos e de ter acesso a informações adequadas sobre reprodução e planejamento familiar;

IV. Conservar sua fertilidade, sendo vedada a esterilização compulsória

V. Exercer o direito à família e à convivência familiar e comunitária;
} 
portador de deficiência. Embora em alguns casos a pessoa se enquadre nas duas hipóteses, como ocorre, quase sempre, com os portadores de deficiência mental.

Estabelecidas as premissas sobre a autoridade parental e os principais aspectos relativos aos portadores de necessidades especiais, interessa aqui estabelecer o conteúdo dessa autoridade na proteção dos direitos dos filhos, especificamente quando portadores de necessidades especiais.

\section{O EXERCÍCIO DA PARENTALIDADE NA PROTEÇÃO DOS DIREITOS DOS FILHOS: ESPECIALMENTE QUANDO SE DESIGUALAM}

O enquadramento do indivíduo na condição de criança ou adolescente faz com que surjam centros de imputação de normas jurídicas específicas, pela peculiar condição de incapacidade desses sujeitos, normas essas traduzidas como direitos das crianças e dos adolescentes.

Tradicionalmente, os bens do homem vêm sendo protegidos tanto pelos efeitos reflexos do direito objetivo como pelo direito subjetivo, sendo suas naturezas diversas. Os bens que aqui nos interessam, são aqueles inerentes à pessoa humana, a saber: a vida, a liberdade e a honra, entre outros. A proteção que se dá a esses bens primeiros do indivíduo são denominados de direitos da personalidade. A designação dessa categoria de direitos com o nome de direitos de personalidade não era, até pouco tempo, unânime na doutrina, nem na jurisprudência. Vamos encontrar diversas denominações, variando a terminologia utilizada pelos autores, originando desta forma, inúmeras controvérsias sobre a natureza desses direitos. Apesar de ser predominante a denominação direitos de personalidade, denominam-nos de direitos sobre a própria pessoa, direitos individuais, direitos personalíssimos, direitos essenciais da pessoa ou fundamentais da pessoa. (SZANIAWSKI, 2005, p. 65).

No caso do portador de necessidades especiais esses direitos de personalidade ganham roupagem própria para minimizar a deficiência, conduzindo, para tanto, ao aparecimento de um conjunto articulado de normas. Como se nota,

O papel da pessoa (biológica) é directo, desde logo, na própria dogmática; tende a haver uma correspondência entre ela e os centros de imputação de normas jurídicas, directa ou instrumentalmente, em moldes que, com facilidade, se deixam antever. Todavia, isso não faculta qualquer instituto: a presença de um centro de imputação de normas não equivale, por si, a qualquer modelo de decisão. Mas para além desse (e de muitos outros) aspectos genéricos, a pessoa (biológica) conduz ao aparecimento de verdadeiros institutos, portanto a conjuntos articulados de normas e de princípios que permitam a figuração de modelos de decisão típicos. (CORDEIRO, 2005, p. 372).

Esse conjunto articulado de normas permite o tratamento diferenciado, na medida em que se desigualam. Isso porque, "toda pessoa com deficiência tem direito à igualdade de oportunidades com as demais pessoas e não sofrerá nenhuma espécie de discriminação". (BRASIL, 2015).

Assim, ao pensar no direito à igualdade deve-se levar em consideração que cada criança e adolescente, independentemente de sua condição, deve ter as mesmas oportunidades asseguradas pelo Estado.

VI. Exercer o direito à guarda, à tutela, à curatela e à adoção, como adotante ou adotando, em igualdade de oportunidades com as demais pessoas. (Art. 6 Lei 13.146/2015). 
Ressalte-se que, os pais, como representantes legais dos seus filhos menores, têm o dever legal de garantir e também promover os direitos fundamentais, muitas vezes de maneira peculiar, por se tratar de menor portador de necessidades especiais.

Inúmeros são os direitos relativos às crianças e aos adolescentes, alguns desses direitos, no entanto, serão tratados especificamente, com enfoque nas peculiaridades decorrentes desta especial condição que enfrentam.

Exatamente por isso, mister se faz a análise dos direitos básicos relativos às crianças e adolescentes, como o direito à saúde, à igualdade, à educação, ao trabalho, entre tantos direitos que devem ser assegurados aos menores, pois configuram o mínimo existencial para o desenvolvimento e a promoção da dignidade humana, aplicados especialmente aos menores portadores de necessidades especiais.

O direito à saúde, por exemplo, como direito social constitucionalmente assegurado, é um direito de todos, cabendo ao Estado promovê-la, de forma integral, à criança e ao adolescente.

A concepção de saúde, no entanto, deve ser ampliada, de forma a abarcar o bem-estar físico, mental e social, afastando a noção de que saúde seria tão somente a ausência de doenças.

Além disso, "o processo de habilitação e de reabilitação é um direito da pessoa com deficiência". BRASIL, 2015)

Como se observa, inúmeras são as medidas adotadas, notadamente no campo da saúde, para proteção e promoção da saúde, entre elas é possível citar a Lei no 8080/90 - Lei Orgânica da Saúde (BRASIL, 1990b), como também a Política Nacional de Saúde da Pessoa Portadora de Deficiência. Além da integração social, cuja Lei no 7853 de 24/10/1989 (BRASIL, 1989) institui a tutela jurisdicional de interesses coletivos e difusos e consolida normas protetivas ao portador de necessidades especiais.

O direito ao lazer também dever ser assegurado a estas crianças e adolescentes, uma das formas de viabilizá-lo está prevista na Lei n. ${ }^{\circ}$ 10.098/2000, no parágrafo único de seu artigo 4º ao estabelecer que:

Os parques de diversões, públicos e privados, devem adaptar, no mínimo, 5\% (cinco por cento) de cada brinquedo e equipamento e identificá-lo para possibilitar sua utilização por pessoas com deficiência ou com mobilidade reduzida, tanto quanto tecnicamente possível. (BRASIL, 2000).

O que ocorre é que muitas vezes tais direitos parecem não ser aplicáveis aos menores portadores de algum tipo de deficiência, como se eles não tivessem direitos, ou, como se fossem invisíveis aos olhos da sociedade.

Durante longo período da história crianças e adolescentes sequer tinham acesso à escola, os pais nem mesmo cogitavam em promover sua educação. $\mathrm{O}$ Estado também não oferecia respaldo para esses pais.

Para uma criança portadora de deficiências, a educação pode ser literalmente vital para sua vida, mais ainda do que para uma criança não deficiente. A inacessibilidade do sistema de ensino - currículos antiquados, critérios de avaliação rígidos, professores com formação insuficiente, falta de recursos, edifícios inacessíveis - talvez tenha mais impacto do que as limitações por parte da criança. Países tão diversos como o Japão, a Argentina, e muitos países do ex-bloco soviético utilizam critérios de diagnóstico para determinar se uma criança 
tem ou não direito à educação, e se for esse o caso, a que tipo de ensino. Frequentemente é a incapacidade que determina o tipo de escola que a criança irá eventualmente frequentar. As opiniões dos pais e da criança, e as capacidades e necessidades efetivas da criança são repetidamente ignoradas. Isto é uma violação direta do direito a uma educação apropriada às aptidões da criança, e do respeito pelas responsabilidades e direitos dos pais, para já não falar dos princípios da não discriminação e do interesse superior da criança. (JONES, 2002, p. 21).

Segundo a atual Constituição brasileira, em seu artigo 208, inciso III, a educação é um direito de todos, sendo que o dever do Estado com a educação será efetivado para os portadores de necessidades especiais, mediante a garantia de atendimento educacional especializado, preferencialmente na rede regular de ensino.

O Estatuto do Portador de Deficiência estabelece em seu artigo 27 que:

A educação constitui direito da pessoa com deficiência, assegurados sistema educacional inclusivo em todos os níveis e aprendizado ao longo de toda a vida, de forma a alcançar o máximo desenvolvimento possível de seus talentos e habilidades físicas, sensoriais, intelectuais e sociais, segundo suas características, interesses e necessidades de aprendizagem.

Parágrafo único. É dever do Estado, da família, da comunidade escolar e da sociedade assegurar educação de qualidade à pessoa com deficiência, colocando-a a salvo de toda forma de violência, negligência e discriminação. (BRASIL, 2015).

Como qualquer criança e adolescente, o menor portador de necessidades especiais tem direito à educação pública e gratuita, assegurada por lei (BRASIL, 1996)7 , preferencialmente na rede regular de ensino e, caso seja necessário, à educação especial, em estabelecimentos de ensino adequados às suas necessidades, devidamente equipados e preparados pelo Poder Público, como determina o artigo 54, III, do Estatuto da Criança e do Adolescente. (BRASIL, 1990).

Em Belo Horizonte, por exemplo, a Lei Orgânica do Município estabelece e garante, nas escolas públicas da rede municipal ou nos particulares conveniados, vagas para as crianças e adolescentes com deficiência. (BELO HORIZONTE, 1990).

Observa-se que matricular os filhos na rede regular de ensino é um dever dos pais, ensejando responsabilidade, pois seu descumprimento pode ser caracterizado como negligência precoce, acarretando, por exemplo, multa $^{8}$ para os responsáveis, enquanto não cumprirem a obrigação de matricular a criança.

O trabalho, por sua vez, é constitucionalmente permitido a partir dos 16 anos, ou na condição de aprendiz a partir dos 14 anos. Em relação ao adolescente portador de necessidades especiais não é diferente. Segundo o Estatuto da Criança e do Adolescente, em seu artigo 66, "ao adolescente portador de deficiência é assegurado trabalho protegido". (BRASIL, 1990).

Para tanto, "a pessoa com deficiência tem direito ao trabalho de sua livre escolha e aceitação, em ambiente acessível e inclusivo, em igualdade de oportunidades com as demais pessoas." (BRASIL, 2015).

Assim, também a Lei n. ${ }^{0} 7.853 / 89$ (BRASIL, 1989) determina que os órgãos e entidades da

\footnotetext{
${ }^{7}$ Art. 58 da Lei n. ${ }^{9} 9394 / 96$.

${ }^{8}$ Nos termos do artigo 213 e 214 do Estatuto da Criança e do Adolescente.
} 
administração direta e indireta devem dispensar, no âmbito de sua competência e finalidade, tratamento prioritário e adequado, tendente a viabilizar, na área da formação profissional e do trabalho, apoio à formação profissional e a garantia de acesso aos serviços concernentes, inclusive aos cursos regulares voltados à formação profissional. Além de outras medidas, como empenho do Poder Público quanto ao surgimento e à manutenção de empregos, inclusive de tempo parcial, destinados às pessoas portadoras de deficiência que não tenham acesso aos empregos comuns, bem como a promoção de ações eficazes que propiciem a inserção, nos setores públicos e privado, de pessoas portadoras de deficiência, além da adoção de legislação específica que discipline a reserva de mercado de trabalho, em favor das pessoas portadoras de deficiência, nas entidades da Administração Pública e do setor privado, e que regulamente a organização de oficinas e congêneres integradas ao mercado de trabalho, e a situação, nelas, das pessoas portadoras de deficiência. (BRASIL, 1989). ${ }^{9}$

Verifica-se que o menor é fisicamente mais frágil e menos resistente que um adulto para o trabalho, ademais como o adolescente ainda está em fase de desenvolvimento o trabalho não pode prejudicar sua saúde e sua educação, além da preocupação com os acidentes de trabalho, haja vista possuírem menos experiência, menos atenção e capacidade para o trabalho que os adultos.

Especialmente em relação aos portadores de necessidades especiais, os pais devem estar atentos às condições laborais. O trabalho deve ser compatível à sua condição, de forma a desenvolver suas habilidades e não diminuir sua capacidade.

Treinar o adolescente portador de necessidades especiais para o trabalho é pressuposto para garantir o seu direito ao trabalho, sua dignidade e integração social.

Não se pode perder de vista que, ntes de ser portador de necessidades especiais o menor é uma criança ou adolescente, dotado de direitos e deveres, como prerrogativa de sua personalidade jurídica.

A lei n.o 7.853 de 1989, visando garantir os direitos das pessoas portadores de necessidades especiais, atribui ao Poder Público, em seu artigo $2^{\circ}$, a responsabilidade de assegurar a estas pessoas o pleno exercício de seus direitos básicos, inclusive dos direitos à educação, à saúde, ao trabalho, ao lazer, à previdência social, ao amparo à infância e à maternidade, e de outros que, decorrentes da Constituição e das leis, propiciem seu bemestar pessoal, social e econômico. (BRASIL, 1989).

Cabe ressaltar que "a acessibilidade é direito que garante à pessoa com deficiência ou com mobilidade reduzida viver de forma independente e exercer seus direitos de cidadania e de participação social." (BRASIL, 2015).

Inúmeros são os direitos relativos às crianças e aos adolescentes, apenas alguns entre tantos direitos foram mencionados para exemplificar os seus direitos básicos. O que não quer dizer que os demais direitos sejam

\footnotetext{
${ }^{9}$ Artigo 2o, parágrafo único, inciso III, alíneas “a”, “b”, "c” e “d”, da Lei n. ${ }^{\text {7 }} .853 / 89$.
} 
menos importantes, ao revés, são indissociáveis e devem ser respeitados com absoluta prioridade, como determina a doutrina de proteção integral.

Obviamente, tais direitos não podem ser vistos de forma isolada. $\mathrm{O}$ arcabouço de direitos fundamentais é um conjunto indivisível de direitos, necessários à sobrevivência desses indivíduos, razão pela qual estão diretamente relacionados para o efetivo cumprimento da dignidade da pessoa humana.

Observe-se ainda, que, "a pessoa com deficiência será protegida de toda forma de negligência, discriminação, exploração, violência, tortura, crueldade, opressão e tratamento desumano ou degradante. Sendo que, para os fins da proteção mencionada no caput deste artigo, são considerados especialmente vulneráveis a criança, o adolescente, a mulher e o idoso, com deficiência”. (BRASIL, 2015).

Nesse ponto, imprescindível a atuação responsável dos pais no exercício da autoridade parental, que em hipótese alguma pode ser usada como subterfúgio para o abuso em seu exercício.

Até porque, para cuidar, educar e criar os filhos os castigos físicos, o tratamento cruel ou degradante está proibido, como determina o Estatuto da Criança e do Adolescente:

Art. 18. É dever de todos velar pela dignidade da criança e do adolescente, pondo-os a salvo de qualquer tratamento desumano, violento, aterrorizante, vexatório ou constrangedor.

Art. 18-A. A criança e o adolescente têm o direito de ser educados e cuidados sem o uso de castigo físico ou de tratamento cruel ou degradante, como formas de correção, disciplina, educação ou qualquer outro pretexto, pelos pais, pelos integrantes da família ampliada, pelos responsáveis, pelos agentes públicos executores de medidas socioeducativas ou por qualquer pessoa encarregada de cuidar deles, tratá-los, educá-los ou protegê-los. (BRASIL, 1990).

Cumpre ressaltar que muitos dos comportamentos relativos às crianças e adolescentes que são inadmissíveis acabam sendo tolerados quando se trata portadores de necessidades especiais, como, por exemplo, pais que abandonam os filhos com algum tipo de deficiência, ou os internam sob a justificativa de tratamento, ou, não os matriculam na escola.

Comportamentos como esses podem ser caracterizados como violência doméstica ${ }^{10}$. Ademais:

É preciso lembrar que a transformação de uma criança em adulto depende de uma enorme quantidade de influências, dentro e fora da casa. Portanto, bater nos filhos, por via das dúvidas, é uma precaução totalmente despida de fundamento. (AZEVEDO, 1995).

Nesse sentido, "é dever de todos comunicar à autoridade competente qualquer forma de ameaça ou de violação aos direitos da pessoa com deficiência." (BRASIL, 2015).

Exatamente por isso, mister se faz a observância obrigatória dos direitos básicos relativos às crianças e adolescentes, como o direito à saúde, à igualdade, à educação, ao trabalho, entre tantos direitos que devem ser assegurados aos menores, pois configuram o mínimo existencial para o desenvolvimento e a promoção da dignidade humana, aplicados especialmente aos menores portadores de necessidades especiais.

Para tanto, o artigo $7^{\circ}$, da Lei n. ${ }^{\circ}$ 13.146/2015, estabelece que:

\footnotetext{
${ }^{10}$ Para verificação das espécies de violência doméstica e suas consequências, permitimo-nos remeter o leitor: BERLINI, Luciana Fernandes. Lei da palmada: uma análise sobre a violência doméstica infantil. Belo Horizonte: Arraes Editores, 2014.
} vol.09, nº. 01, Rio de Janeiro, 2016.pp. 425-440 
É dever do Estado, da sociedade e da família assegurar à pessoa com deficiência, com prioridade, a efetivação dos direitos referentes à vida, à saúde, à sexualidade, à paternidade e à maternidade, à alimentação, à habitação, à educação, à profissionalização, ao trabalho, à previdência social, à habilitação e à reabilitação, ao transporte, à acessibilidade, à cultura, ao desporto, ao turismo, ao lazer, à informação, à comunicação, aos avanços científicos e tecnológicos, à dignidade, ao respeito, à liberdade, à convivência familiar e comunitária, entre outros decorrentes da Constituição Federal, da Convenção sobre os Direitos das Pessoas com Deficiência e seu Protocolo Facultativo e das leis e de outras normas que garantam seu bem-estar pessoal, social e econômico. (BRASIL, 2015).

A análise proposta permite efetivamente garantir o respeito à população infanto-juvenil portadora de necessidades especiais, por meio de um tratamento diferenciado, nos aspectos em que se diferenciam.

Sendo que a não observância, pelos genitores, da especial condição que enfrentam esses menores, no exercício da autoridade parental, pode ser o fator desencadeante da violação dos direitos desses filhos especiais.

Trata-se de dar visibilidade e importância a uma minoria esquecida pela sociedade, vítima da própria sorte, crianças e adolescentes portadores de necessidades especiais precisam de proteção e reconhecimento, mesmo quando seus pais não conseguem fazê-lo.

Estudos em pequena escala revelam que alguns grupos de crianças são particularmente vulneráveis à violência, como crianças portadoras de deficiências, crianças de minorias e outros grupos marginalizados, "crianças de rua" e crianças em conflito com a lei, refugiadas e deslocadas. (ASSEMBLÉIA GERAL DAS NAÇÕES UNIDAS, 2006).

Assim:

Quando a autoridade se apresenta não como entidade castradora ou opressora, mas formadora e protetora, a criança se vê continuada nos próprios pais. Ao contrário, quando ela se vê explorada ou de alguma forma neutralizada, o que ela vê não são os seus protetores, mas os seus inimigos mais direitos. (HIRONAKA, 2002, p. 429).

As dificuldades e preconceitos que muito provavelmente essas crianças e adolescentes portadores de necessidades especiais enfrentarão, não podem ser agravados pelos pais. Muito pelo contrário, como representantes legais que são, os pais têm a obrigação de minimizar as dificuldades e evitar o preconceito, promovendo de forma plena e segura o desenvolvimento de seus filhos. Até porque o preconceito ainda é uma grande deficiência a ser enfrentada.

Assim, no exercício da autoridade parental deve levar-se em conta, no caso concreto, a adoção de medidas que atendam ao melhor interesse da criança (e do adolescente $)^{11}$, como prerrogativa da doutrina jurídica de proteção integral, nos moldes do artigo $3^{\circ}$ do Estatuto da Criança e do Adolescente:

A criança e o adolescente gozam de todos os direitos fundamentais inerentes à pessoa humana, sem prejuízo da proteção integral de que trata esta Lei, assegurando-se-lhes, por lei ou por outros meios, todas as oportunidades e facilidades, a fim de lhes facultar o desenvolvimento físico, mental, moral, espiritual e social, em condições de liberdade e de dignidade. (BRASIL, 1990).

O princípio do melhor interesse da criança é de observância obrigatória, sob pena de comprometer os

\footnotetext{
${ }^{11}$ Embora esse princípio jurídico seja denominado princípio do melhor interesse da criança seu conteúdo abrange a criança e o adolescente.
} 
direitos fundamentais infanto-juvenis, o que enseja, por conseguinte, o respeito de todos, em todos os casos.

A adoção, em sede constitucional, da doutrina da proteção integral veio afirmar o princípio do melhor interesse da criança, já existente em nossa legislação e que encontra suas raízes na Declaração Universal dos Direitos da Criança, adotada pela ONU em 20 de novembro de 1959. (BARBOZA, 2000, p. 204).

O que se observa é que o princípio do melhor interesse da criança perfaz-se através da concretização da doutrina da proteção integral, que não admite qualquer forma de violação dos direitos de crianças e adolescentes.

De tal forma que a adoção do princípio do melhor interesse da criança deve ocorrer em todos os casos, por concretizar o sistema de proteção integral trazido no âmbito constitucional e reiterado pelo Estatuto.

A incorporação da doutrina da proteção integral no corpo constitucional ratificou e explicitou o princípio do melhor interesse da criança, aplicável a toda criança e adolescente. Em consequência, a partir de 1988, passaram tal doutrina e princípio a reger, necessariamente, as relações familiares que envolvam criança e adolescente. (BARBOZA, 2000, p. 207).

"É isso, principalmente, o que os modernos nos mostram a respeito da responsabilidade nas relações de família: elas só são legítimas enquanto se concentram no interesse pela formação e pela liberdade dos filhos”. (HIRONAKA, 2002, p. 431).

A observância, nessa perspectiva, do princípio do melhor interesse da criança não atende só às necessidades do menor em desenvolvimento, é, também, premissa constitucional abarcada pelo sistema de proteção integral, que deve ser respeitada.

Tanto é assim que o Estatuto da Criança e do Adolescente não apenas adotou o referido princípio, como expressamente determinou que sua observância deva ocorrer também na adoção de medidas específicas de proteção à criança, de modo que a "intervenção deve atender prioritariamente aos interesses e direitos da criança e do adolescente, sem prejuízo da consideração que for devida a outros interesses legítimos no âmbito da pluralidade dos interesses presentes no caso concreto". (BRASIL, 1990) $)^{12}$

É, desse modo, inquestionável que os direitos da população infanto-juvenil só serão respeitados se for aplicado o princípio do melhor interesse da criança. Isso porque, a observância desse princípio, analisado a partir do caso concreto, que sugere uma série de variáveis e possibilidades, permite a adequação das normas, ainda que estejam em conflito.

Tem-se, dessa forma, um parâmetro objetivo de aplicação das normas referentes às crianças e aos adolescentes, viabilizado por tal princípio, o que possibilita concretizar os direitos fundamentais sem contudo, estabelecer um escalonamento de direitos a priori.

É a partir do caso concreto que se verificará a melhor solução para a criança portadora de necessidades especiais, caso haja a violação de algum de seus direitos, em consonância com o princípio do melhor interesse, capaz de garantir em todos os casos a promoção da dignidade da pessoa humana.

${ }^{12}$ Artigo 100, parágrafo único, inciso IV, do Estatuto da Criança e do Adolescente. vol.09, n. 01, Rio de Janeiro, 2016.pp. 425-440 
Assim, o princípio do melhor interesse da criança e do adolescente portador de necessidades especiais deve ser observado, sem perder de vista sua real dimensão, que ora nenhuma abrange ou tolera qualquer tipo de violação aos seus direitos, pois é corolário do sistema de proteção integral, a que toda criança e adolescente estão submetidos.

\title{
CONSIDERAÇÕESFINAIS
}

O menor portador de necessidades especiais é, antes de tudo, uma criança ou adolescente e, como tal, goza de especial proteção, contando com um sistema de proteção integral previsto na Constituição da República de 1988 e detalhado no Estatuto da Criança e do Adolescente.

Quando se trata de crianças e adolescentes portadores de necessidades especiais tal sistema de proteção integral faz-se ainda mais importante, tendo especificidades e aplicabilidade compatíveis com a peculiar condição desses menores, como pressuposto de uma nova e imprescindível demanda social.

Os pais, como representantes legais dos seus filhos menores, têm o dever legal de garantir e também promover a eles os direitos fundamentais, muitas vezes de maneira peculiar, por se tratar de menor portador de necessidades especiais,

Dessa forma, o exercício da parentalidade deve-se pautar no atendimento ao melhor interesse da criança, de forma condizente com sua especial condição.

Isso porque, quando se trata de crianças e adolescentes portadores de necessidades especiais a inclusão deve começar em casa. Daí a importante atuação dos genitores, nesse processo, de minimizar as barreiras enfrentadas por seus filhos na busca pela concretização do direito à igualdade substancial e promoção dos demais direitos.

\section{THE EXERCISE OF PARENTING WHEN THE CHILD HAS SPECIAL NEEDS}

\begin{abstract}
The exercise of parental authority requires a new interpretation of the civil law, specifically when the offspring have special needs. This is because the combination of the peculiar status of special needs conjugated to the fact of being children and adolescents and therefore, incapable, highlights the vulnerable situation faced. Thus, the protection of children and adolescents begins with the analysis of the exercise of parental authority, whereas parents are, as a rule, the legal representatives of their minor children, such that is from these relationships that you can observe the respect of the rights and guarantees of children and adolescents, especially when they have special needs, tracing the new guidelines established by the Brazilian Law of Inclusion of People with Disabilities (Statute of People with Disabilities).
\end{abstract}

Keywords: The Exercise of Parental Authority. Child With Special Needs. 


\section{REFERENCIAS}

ALBUQUERQUE, Fabíola Santos. Poder familiar nas famílias recompostas e o art. 1.636 do CC/2002. In: Congresso Brasileiro de Direito de Família, 4, 2003, Belo Horizonte. Anais... Belo Horizonte: IBDFAM, Ordem dos Advogados do Brasil, 2004.

AZEVEDO, Maria Amélia. A violência doméstica na infância e na adolescência. São Paulo: Robel Editorial, 1995.

ASSEMBLÉIA GERAL DAS NAÇÕES UNIDAS. Estudo das Nações Unidas sobre a violência contra crianças. 23 ago. 2006. Disponível em: <http://www.unicef.org/brazil/pt/Estudo_PSP_Portugues.pdf. > Acesso em: 2 jul.2015.

BARBOZA, Heloisa Helena. O princípio do melhor interesse da criança e do adolescente. In: Congresso Brasileiro de Direito de Família, 2, 1999, Belo Horizonte Anais...Belo Horizonte: Del Rey, 2000. p. 202.

BORZONE, Graciela. La protecion contra toda forma de violencia en la convencion de los derechos del niño. In: Maltrato y Violência Infantil. Buenos Aires: Nuevo Pensamiento Judicial Editora, 2003.

BELO HORIZONTE. Câmara Municipal. Lei Orgânica. 1990. Disponível em: < http://www.cmbh.mg.gov.br/leis/legislacao/lei-organica. > Acesso em: 17 jul. 2015.

BERLINI, Luciana Fernandes. Lei da palmada: uma análise sobre a violência doméstica infantil. Belo Horizonte: Arraes Editores, 2014.

BRASIL. Presidência da República. Casa Civil. Subchefia para Assuntos Jurídicos. Lei n 8.069, de 13 de julho de 1990: dispõe sobre o Estatuto da Criança e do Adolescente, e dá outras providências. Diário Oficial da União, Brasília, 16 jul. 1990. Disponível em: < http://www.planalto.gov.br/ccivil_03/leis/L8069.htm> Acesso em: 13 jul. 2015.

Presidência da República. Casa Civil. Subchefia para Assuntos Jurídicos. Lei no 10.048 , de 8 de novembro de 2000: dá prioridade de atendimento às pessoas que especifica, e dá outras providências. Diário Oficial da União, Brasília, 9 nov. 2000a. disponível em: < http://www.planalto.gov.br/ccivil_03/leis/L10048.htm> Acesso em: 13 jul. 2015.

Presidência da República. Casa Civil. Subchefia para Assuntos Jurídicos. Lei ${ }^{\circ}$ 10.098, de 19 de dezembro de 2000: estabelece normas gerais e critérios básicos para a promoção da acessibilidade das pessoas portadoras de deficiência ou com mobilidade reduzida, e dá outras providências. Diário Oficial da União, Brasília, 20 dez. 2000b. Disponível em: http://www.planalto.gov.br/ccivil_03/leis/L10098.htm> Acesso em: 13 jul. 2015.

Presidência da República. Casa Civil. Subchefia para Assuntos Jurídicos. Lei 7.853 de 24 de outubro de 1989: Dispõe sobre o apoio às pessoas portadoras de deficiência, sua integração social, sobre a Coordenadoria Nacional para Integração da Pessoa Portadora de Deficiência - Corde, institui a tutela jurisdicional de interesses coletivos ou difusos dessas pessoas, disciplina a atuação do Ministério Público, define crimes, e dá outras providências. Diário Oficial da União, Brasilia, 25 out. 1989. Disponível em: <http://www.planalto.gov.br/ccivil_03/leis/L7853.htm> Acesso em: 13 jul. 2015.

Presidência da República. Casa Civil. Subchefia para Assuntos Jurídicos. Lei No 9.394 de 20 de dezembro de 1996: estabelece as diretrizes e bases da educação nacional. Diário Oficial da União, Brasília, 23 dez. 1996. Disponível em: < http://www.planalto.gov.br/ccivil_03/leis/L9394.htm> Acesso em: 13 jul. 2015.

Presidência da República. Casa Civil. Subchefia para Assuntos Jurídicos. Lei № 10.406 de 10 de janeiro de 2002: institui o Código Civil. Diário Oficial da União, Brasília, 11 jun. 2002. Disponível em: < 
http://www.planalto.gov.br/ccivil_03/leis/2002/L10406.htm> Acesso em: 13 jul. 2015.

Presidência da República. Casa Civil. Subchefia para Assuntos Jurídicos. Lei no 13.146, de 6 de julho de 2015: Institui a Lei Brasileira de Inclusão da Pessoa com Deficiência (Estatuto da Pessoa com Deficiência). Diário Oficial da União, Brasília, 7 jul. 2015. Disponível em: http://www.planalto.gov.br/ccivil_03/_Ato20152018/2015/Lei/L13146.htm. Acesso em: 16 jul. 2015.

Ministério da Saúde.Secretaria de Políticas de Saúde Departamento de Atenção Básica. Secretaria de Atenção à Saúde Departamento de Ações Programáticas Estratégicas. Manual de legislação em saúde da pessoa portadora de deficiência. 2. ed. rev. e atual. Brasília: Ministério da Saúde, 2006.

CORDEIRO, António Menezes. Tratado de direito civil português. 3. ed. Coimbra: Almedina, 2005. p. 372. v.1. t.1.

COUTINHO, Leonardo. Crimes na floresta. Veja, São Paulo, n² 2021, p. 106, 15 ago.2007.

DINIZ, Maria Helena. O estado atual do biodireito. 4. Ed. São Paulo: Saraiva, 2007.

FACHIN, Luiz Edson. Elementos críticos do direito de família: curso de direito civil. Rio de Janeiro: Renovar, 1999.

GARBARINO, James. ECKENRODE, John. Por qué las familias abusan de sus hijos. Espanha: Granica; 1999. p.45-83.

GONZÁLEZ, Eugênio. Necessidades educacionais especificas. Trad. Dayse Vaz de Moraes. Porto Alegre: Artmed, 2007.

HIRONAKA, Giselda Maria Fernandes Novaes. Direito e responsabilidade. Belo Horizonte: Del Rey, 2002.

JONES, Hazel. Os direitos das crianças portadoras de deficiências: um guia prático. Trad. de Octávio Gameiro. Impresso por Bergs Grafiska AB 2002.

LÔBO, Paulo Luiz Netto. Entidades familiares constitucionalizadas. In: Congresso Brasileiro de Direito de Família, 3, 2001, Ouro Preto, MG. Anais. Belo Horizonte: IBDFAM, Ordem dos Advogados do Brasil, 2002.p. 95

LÔBO, Paulo Luiz Netto. Do poder familiar. Jus Navigandi, Teresina, ano 10, n. 1057, 24 maio 2006. Disponível em: <http://jus2.uol.com.br/doutrina/texto.asp?id=8371 >. Acesso em: 14 jul. 2015.

LONGO, Cristiano da Silveira. A punição corporal doméstica de crianças e adolescentes: o olhar de autores de livros sobre educação familiar no Brasil (1981-2000). São Paulo: Ieditora, 2002.

MATEOS, Roberto José María. Violencia contra niños y adolescentes. In: Maltrato y Violência Infantil. Associacion Argentina para la Infancia. Buenos Aires: Nuevo Pensamiento Judicial Editora, 2003.

SZANIAWSKI, Elimar. Direitos de personalidade e sua tutela. 2 ed. São Paulo: Revista dos Tribunais, 2005.

TEIXEIRA, Ana Carolina Brochado. Família, guarda e autoridade parental. Rio de Janeiro: Renovar, 2008.

Trabalho enviado em 18 de agosto de 2015.

Aceito em 10 de novembro de 2015. 